\title{
SAFETY AND IMMUNOGENICITY OF HAEMOPHILUS INFLUENZAE TYPE B CONJUGATE VACCINE IN COPD
}

\author{
Mahaboob Khan', M. Shahana ${ }^{2}$
}

${ }_{1}^{1}$ Associate Professor, Department of Pulmonary Medicine, Gandhi Medical College.

${ }^{2}$ Assistant Professor, Department of Pulmonary Medicine, Gandhi Medical College.

\begin{tabular}{l} 
ABSTRACT \\
\hline BACKGROUND
\end{tabular}

To evaluate the safety and immunogenicity of Haemophilus influenzae type B conjugate vaccine in COPD.

\section{MATERIALS AND METHODS}

48 stable COPD cases from the admission in to the Pulmonary Medicine Department of Govt. General \& Chest Hospital, Hyderabad were given $0.5 \mathrm{~mL}$ of conjugated Hib vaccine.

\section{RESULTS}

The seroconversion rates: 40 (90.9\%) and 44 (100\%) at visit-1 (pre-vaccinated) and visit-3 (post-vaccinated) respectively. Seroprotection rates: 18 (40.9\%) and 43 (97.7\%) at visit-1 (pre-vaccinated) and visit-3 (Post vaccinated) respectively. GMT values: 0.7 micrograms $/ \mathrm{mL}$ and 2.9 micrograms/mL at visit- 1 and visit-3 respectively. More than 4 -fold increase in GMT values by visit-3 was observed, P value- 0.00002. 22 (50\%) subjects showed 4-fold increase in antibody titre from pre-vaccination to post-vaccination. Four mild adverse events reported. Out of 44 subjects, $4(9.09 \%)$ reported pain and redness at site of vaccination.

\section{CONCLUSION}

Hib vaccine is safe and immunologically effective in COPD at the dosage tested by producing 4-fold increases in anti-PrP antibody titres in comparison with baseline titres.

\section{KEYWORDS}

Conjugated Vaccine, Seroprotection, Seroconversion.

HOW TO CITE THIS ARTICLE: Khan M, Shahana M. Safety and immunogenicity of Haemophilus influenzae type B conjugate vaccine in COPD. J. Evolution Med. Dent. Sci. 2016;5(81):6067-6069, DOI: 10.14260/Jemds/2016/1370

\begin{abstract}
BACKGROUND
Haemophilus influenzae is a common Gram-negative humanrestricted bacterial pathogen that frequently colonises the nasopharynx in healthy individuals and can cause local infections such as otitis media, sinusitis, pneumonia, or exacerbations of chronic obstructive pulmonary disease (COPD). Exacerbation of COPD will increase the burden on morbidity and mortality and it will have economic burden for the patients especially in developing countries such as India. Exacerbated COPD is usually associated with increased airway and systemic inflammation that causes the physiological changes which leads to the development of hyperinflation. The exacerbated COPD is usually triggered by virus and bacterial infection of lower respiratory tract, in response some patients develop exacerbated COPD. Drugs like long acting beta 2 agonist and long acting steroids or their combination may be effective in control of exacerbated COPD. Pulmonary rehabilitation, self-management and house ventilator support have got their own importance in the management of exacerbated COPD, but it requires further controlled trials.
\end{abstract}

Financial or Other, Competing Interest: None.

Submission 19-08-2016, Peer Review 27-09-2016,

Acceptance 03-10-2016, Published 10-10-2016.

Corresponding Author:

Dr. Mahaboob Khan,

Gandhi Medical College/Govt. General and Chest Hospital,

Hyderabad, Telangana State,

India.

E-mail:dr_mahaboob@yahoo.com

DOI: $10.14260 /$ jemds $/ 2016 / 1370$

(c) $($ ) $९$
The results of exacerbated COPD depends upon the optimum use of the combination of both pharmacological and non-pharmacological drugs and it will increase the health status and decrease the hospital admission and mortality of COPD.

In the recent past, epidemiology and clinical manifestations of $\mathrm{H}$. influenzae infection underwent major changes. The use of vaccines almost eradicated the $H$. influenzae infection in developed countries where vaccines are used routinely. Higher rates of infection were observed in pre-vaccinated era and in developing countries like India where vaccination is not used regularly. These vaccines have got both genetic and acquired components in protecting immune response.

When the bacteria breach the epithelial barriers, they are able to cause invasive disease, including meningitis, sepsis, and epiglottitis.1,2 Most invasive infections are caused by encapsulated strains, in particular H. influenzae type B (Hib), characterised by a polyribosylribitol phosphate (PrP) capsule, which is an important virulence factor. In immune individuals, circulating anti-PrP antibodies effectively protect against the disease by activating the classical complement pathway, as well as opsonising bacteria for phagocytosis. ${ }^{3}$ In the present study, safety and efficacy of Hib vaccine has been studied.

\section{AIM OF THE STUDY}

Evaluating the immunogenicity and safety of Haemophilus influenzae type-B conjugate vaccine (Hib) in stable COPD patients. 


\section{MATERIALS AND METHODS}

Setting

650-bed tertiary referral hospital.

\section{Study Design}

Randomised, open label, prospective clinical study.

\section{Subjects}

48 stable COPD patients attending the outpatient department during the period of May to September 2015

- No. of subjects enrolled-48.

- No. of subjects who completed study-44.

- No. of subjects who discontinued study-4.

\section{Inclusion Criteria}

Written Consent

1. Stable COPD patients (mild-to-moderate) of either sex between 30-64 yrs. at the time of consent.

2. Spirometry values- FEV1\% predicted $30-80 \%$, FEV1/FVC $<70 \%$ predicted without bronchodilator.

3. Non-pregnant and non-lactating females.

4. Not participating in any clinical trials.

5. Normal body temperature.

6. Not on immunosuppressive therapy.

7. No serious (life threatening) comorbid conditions.

\section{Exclusion Criteria}

1. H/O Asthma, allergic rhinitis, atopy.

2. On screening, increase in FEV1 more than or equal to $12 \%$ of the pre-dose value after inhalation of salbutamol 400 micrograms.

3. Subjects with any contagious disease.

4. Any history of allergic disease likely to be precipitated by any component of the vaccine.

\section{Composition and Dosage}

Each single dose of $0.5 \mathrm{~mL}$ contains lyophilised preparation of H. influenzae type-B capsular polysaccharide (PrP)-10 micrograms (Conjugated to 20 micrograms of inactivated tetanus toxoid). $0.5 \mathrm{~mL}$ single dose deep IM over deltoid.

\section{Criteria for Evaluation}

Proportion of subjects- seroconverted $\quad(>0.15$ micrograms $/ \mathrm{mL}$ ), seroprotected ( $>1 \operatorname{microgram} / \mathrm{mL}$ ) and attained 4-fold raise in anti-PrP antibody titre level at $28^{\text {th }}$ day.

Proportion of subjects showing untoward medical occurrences, all episodes of abnormal finding (including laboratory values) \& subjective and objective symptoms of disease during the study.

\section{Study Protocol}

Clinical features and physical examination

Investigations.

CBP, RBS, LFT, CUE, RFT.

Sputum for AFB, CXR PA view, PFT and anti-PrP antibody assay (ELISA).

\section{RESULTS}

The seroconversion rates $-40(90.9 \%)$ and $44(100 \%)$ at visit1 (pre-vaccinated) and visit-3(post-vaccinated) respectively.

\section{Seroconversion}

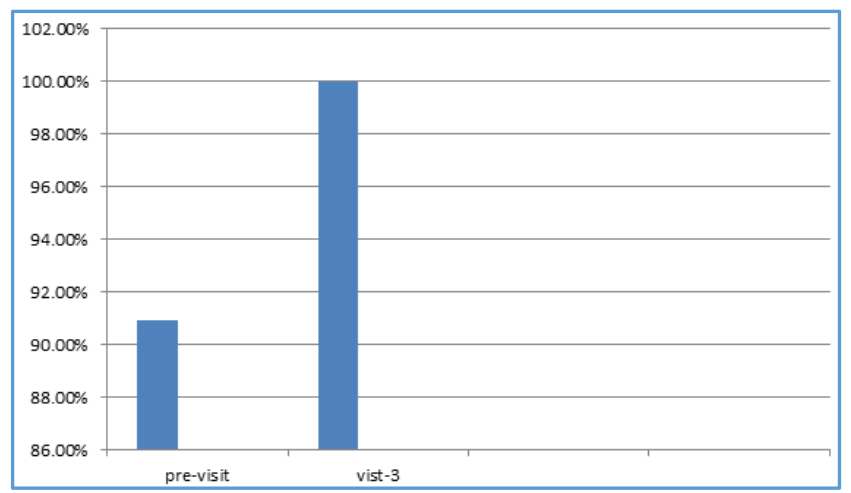

Seroprotection rates-18(40.9\%) and $43(97.7 \%)$ at visit-1 (pre-vaccinated) and visit-3 (post-vaccinated) respectively. The $P$ value $<0.0001$.

\section{Seroprotection}

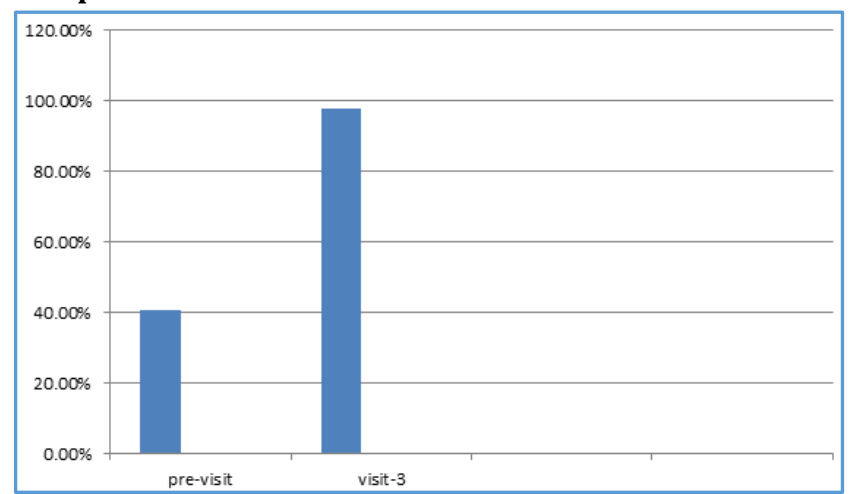

GMT values 0.7 micrograms/mL and 2.9 micrograms $/ \mathrm{mL}$ at visit- 1 and visit- 3 respectively. More than 4 -fold increase in GMT values by visit- 3 was observed, $P$ value- 0.00002 .

$22(50 \%)$ subjects showed 4 -fold increase in antibody titre from pre-vaccination to post-vaccination.

Four mild adverse events reported. Out of 44 subjects, 4 (9.09\%) reported pain and redness at site of vaccination.

No serious adverse events reported during study period.

\section{DISCUSSION}

In $97 \%$ of healthy unvaccinated adults, circulating IgG antibodies against Hib capsular polysaccharide were above the level ensuring longterm protection against invasive $\mathrm{Hib}$ disease, i.e. $0.15 \mu \mathrm{g} / \mathrm{mL}(\underline{3})$; Moreover, $56 \%$ of healthy individuals had antibody levels of $\geq 1 \mu \mathrm{g} / \mathrm{mL}$, a correlate of protection in the vaccinated population ${ }^{4}$, which is similar to the present study. These data suggest that the general adult population is well protected against invasive Hib disease, which is indeed extremely rare in healthy adults. ${ }^{5}$ Because none of the subjects had been vaccinated against Hib, natural anti-Hib antibodies may have been induced by exposure to some common environmental bacteria that carry antigens cross-reacting with PrP such as Escherichia coli K $100 .{ }^{6}$

In compliance with earlier studies, we considered serum IgG anti-PrP levels the major indicator of protection against Hib invasive disease. ${ }^{7} \mathrm{~A}$ similar discordance between anticapsular IgG levels and their functional activity had previously been documented in response to vaccination against Hib and Neisseria meningitidis serogroup C.8,9 
In the present study, we did not see a correlation between anti-PrP IgG levels and serum bactericidal activity.

Our study correlates with the recent data on emerging invasive Hib disease in unimmunised adults, provide a rationale for extended indications for immunisation of vulnerable groups of adults against Hib.10,11

It was found that the major cause of exacerbated COPD is the infection which contributes $50 \%$. Heart failure contributes nearly $20 \%$ - 25\% of exacerbated COPD. Approximately, $30 \%$ of exacerbated COPD will not have proved aetiology. Environmental pollution like sulphur dioxide $\left(\mathrm{SO}_{2}\right)$, ozone $\left(\mathrm{O}_{3}\right)$ and nitrogen dioxide $\left(\mathrm{NO}_{2}\right)$ are also contributing in producing exacerbated COPD, outdoor and indoor pollution also impact in developing exacerbated COPD. In India, especially in rural areas, the burring of animal dung also is a common factor for exacerbated COPD. Firewood for cooking purpose in certain parts of country and use of pesticides in agriculture are also contributing for the exacerbated COPD.

\section{CONCLUSIONS}

There was significant evidence in the aetiology and pathogenesis of Exacerbated COPD. It was concluded that the airway inflammation is the main reason for the Exacerbated COPD which leads to Exacerbated COPD. It was found that the main causes for the Exacerbated COPD are bacterial, viral and environmental factors. The mortality increases with each episode of Exacerbated COPD, hence importance should be given to treatment and prevention of exacerbated COPD. But still further control trials are needed to manage Exacerbated COPD to the expected level.

Hib vaccine is both safe and immunologically effective in COPD at the dosage tested by producing 4-fold increases in anti-PrP antibody titres in comparison with baseline titres.

Further authentic and long term trials are required to confirm our results and the effectiveness of Hib vaccine in COPD patients.

Frequency of administration and combination with other vaccines (Pneumovax) has to be evaluated.

\section{ACKNOWLEDGEMENT}

- We are thankful to doctors and staff of Govt. Genl. \& Chest Hospital, Hyderabad, for their cooperation in conducting the study.

- Dr. P.N.S. Reddy, Professor of TBCD, Govt. Genl. \& Chest Hospital, Hyderabad for his guidance and cooperation.
- Ethical committee of Govt. Genl. \& Chest Hospital, Hyderabad.

- Postgraduates of Govt. Genl. \& Chest Hospital, Hyderabad.

\section{REFERENCES}

1. Moxon ER. The carrier state: Haemophilus influenzae. J Antimicrob Chemother 1986;18(Suppl A):17-24.

2. Murphy TF. Haemophilus infections. In: Mandell GL, Douglas RG, Bennett JE, et al. eds. Bennett's principles and practice of infectious diseases. Vol 2. $6^{\text {th }}$ edn. New York, NY: Elsevier 2005:2661-9.

3. Schreiber JR, Barrus V, Cates KL, et al. Functional characterization of human $\lg \mathrm{G}, \lg \mathrm{M}, \lg \mathrm{A}$ antibody directed to the capsule of Haemophilus influenzae type b. J Infect Dis 1986;153(1):8-16.

4. Anderson P. The protective level of serum antibodies to the capsular polysaccharide of Haemophilus influenzae type $b$. J Infect Dis 1984;149(6):1034-5.

5. Takala AK, Eskola J, van Alphen L. Spectrum of invasive Haemophilus influenzae type b disease in adults. Arch Intern Med 1990;150(12):2573-6.

6. Insel RA, Anderson PW. Cross-reactivity with Escherichia coli K 100 in the human serum anticapsular antibody response to Haemophilus influenzae type B. J Immunol 1982;128(3):1267-70.

7. Kayhty H, Peltola H, Karanko V, et al. The protective level of serum antibodies to the capsular polysaccharide of Haemophilus influenzae type b. J Infect Dis 1983;147(6):1100.

8. Amir J, Liang X, Granoff DM. Variability in the functional activity of vaccine-induced antibody to Haemophilus influenzae type b. Pediatr Res 1990;27(4 Pt 1):358-64.

9. Maslanka SE, Tappero JW, Plikaytis BD, et al. Agedependent Neisseria meningitidis serogroup C classspecific antibody concentrations and bactericidal titres in sera from young children from Montana immunized with a licensed polysaccharide vaccine. Infect Immun 1998;66(6):2453-9.

10. Rubach MP, Bender JM, Mottice S, et al. Increasing incidence of invasive Haemophilus influenzae disease in adults, Utah, USA. Emerg Infect Dis 2011;17(9):1645-50.

11. Shuel M, Law D, Skinner S, et al. Characterization of nontypeable Haemophilus influenzae collected from respiratory infections and invasive disease cases in Manitoba, Canada. FEMS Immunol Med Microbiol 2010;58(2):277-84. 